\title{
Becoming Men: Gender, Disability, and Transitioning to Adulthood
}

This is the pre -peer review version of an article published online. Citation:

B.E. Gibson, B Mistry, B Smith, KK Yoshida, D Abbott, S Lindsay, and Y Hamdani (2013 online) Becoming Men: Gender, Disability, and Transitioning to Adulthood. Health. doi: $10.1177 / 1363459313476967$

\author{
Corresponding Author \\ Barbara E. Gibson \\ Department of Physical Therapy \\ University of Toronto \\ Email: barbara.gibson@utoronto.ca
}

\begin{abstract}
:
Children and youth with progressive conditions are living longer, and there is increased interest in designing programs that will assist them with 'transitioning' to adulthood. Almost none of the transitions research to date, however, has attended to the experiences of disabled boys in 'becoming men'; nor has there been critical conceptual work problematizing notions of 'normal' adulthood or theorizing the complex, diverse and gendered experiences of transitioning. In this Canadian study we investigated the intersectionality of gender, disability, and emerging adulthood with 15 young men with Duchenne Muscular Dystrophy. Participants created audio diaries and photographs that were explored in in-depth interviews. Using a Bourdieusian lens and Arthur Frank's (2010) notion of the narrative habitus we examined how participants re/negotiated identities in everyday practices. Our analysis suggested disability, masculinities and generational (life stage) identities intersected through 'narratives of non-difference', wherein participants worked to establish identities as typical 'guys'. Within limited fields of school and work, participants distanced themselves from the label of 'disabled' and discussed their successes and challenges in terms of normative developmental trajectories. We suggest that the pursuit of 'normal' is reproduced and reinforced in health and social programs and closes off other narratives and possibilities.
\end{abstract}

Key words: disability, youth, masculinities, critical, muscular dystrophy 
Young people with conditions previously limited to childhood (e.g. muscular dystrophy, cystic fibrosis, spina bifida) are living longer, and there is increased interest in designing health and social programs that will assist them with 'transitioning' to adulthood (Beresford 2004). Normative assumptions regarding what constitutes a successful transition and by implication a 'good' adulthood are pervasive in research and practice. Transitions research has identified barriers and challenges for young people, including difficulties in finding work or accommodated higher learning (Priestley et al. 2003), feelings of social isolation (Morris 2002), tensions with family members related to over-protectiveness or low expectations (Stewart et al., 2001) and lack of available adult health services (Binks et al., 2007). Only a few studies, however, have critically examined the dominance of the 'normal' life course in transitions programs and the effects on youth (Bjarnason 2002; Aitchison 2003).

Moreover, very little of the research to date has attended to the gendered experiences of transitioning. Some research is available demarcating differences in transition outcomes and health behaviours e.g., lower wages for young women, gender bias in vocational training, higher risk-taking behaviours with young men (Berge et al., 2007; Powers et al., 2008 ;Willis et al., 2001); but little work has critically explored how gender and disability intersect in mediating transitions. To our knowledge, no studies with disabled men have specifically examined issues of transition to adulthood. This is problematic as both gender and generation (life stage) denote hierarchical social orderings and cultural distinctions between social groups. As children age they are implicitly expected and expect to acquire the abilities, privileges, responsibilities and characteristics associated with the prevailing socio-cultural understandings of adulthood and gendered roles (Priestley 2003; Walkerdine 1993). We know very little about how these intersecting structures mediate disabled men's identities, experiences of social inclusion, or their psychosocial wellbeing. Research has demonstrated myriad ways that hegemonic notions of masculinity such as strength, courageousness, independence and self-reliance may be (re)negotiated, relied upon, or resisted by disabled men (Gibson et al., 2007; Sparkes and Smith 2002; Shakespeare 1999; Shuttleworth 2000; Abbott 2012). Nevertheless there remains a paucity of research with disabled men in general and particularly young men with progressive or life-long conditions (Shuttleworth et al., 2012).

To address these issues we undertook a critical qualitative study investigating the intersectionality of gender, disability and emerging adulthood with young men with Duchenne Muscular Dystrophy (DMD). DMD is a genetic condition that exclusively affects males and is characterized by progressive weakening of skeletal muscle. This population has been largely excluded from transitions research to date, likely in part because it is only in the last 15 to 20 years that their expected life span has extended past childhood. With new interventions, individuals with DMD can now live into their 30 s or 40 s and life expectancy continues to increase. In their teens, youth with DMD begin using power wheelchairs for mobility and require assistance with activities of daily living including eating, dressing, and toileting. Because of progressive weakness of their respiratory muscles, youth in their late teens and twenties increasingly require mechanical ventilation, initially at night only and eventually for 24 hours a day. As individuals age they require increasing assistance with activities of daily living which may be provided by paid attendants and/or family members. 


\section{A Critical Bourdieusian Approach}

The study was grounded in a critical approach that drew on the work of Pierre Bourdieu (1984, 1990, 1997; Bourdieu and Wacquant 1992). Bourdieu's central concept of habitus, which can be described as a set of dispositions that incline persons towards particular practices in given contexts, provided an explanatory lens for analysing the interplay between individual attitudes and behaviours and internalized social norms and patterns of behavior (Bourdieu 1990: 7-10). Habitus operates in relation to fields which can be described as social microcosms such as the family, health care, or education which valorize or discredit particular forms of capital. In the study, we examined the relationships between hierarchical field positions (dominant, subordinate, marginalized, complicit) and participants' everyday strategic practices in accomplishing their gendered identities (Coles 2009; Connell 1995). Identity work was thus linked with claiming or rejecting membership in particular social groups and the (largely 'unconscious') strategies participants engaged in to improve their positioning within these groups (Bourdieu 1997; Gibson et al., 2007). Our analysis focused on explicating how these strategies emerged and their effects. We drew from Arthur Frank's (2010) notion of the narrative habitus to examine how, through their accounts, participants revealed the constant re/negotiation of identities in everyday practices. Narrative habitus can be described as the embodied, unreflective affinity to some stories over others that leads to them being taken up and employed in the telling of one's own life (Sparkes et al., 2012).

In the paper we draw from Priestley's (2003:19-25) use of 'generation' to denote an age-related life stage and social category (e.g., childhood, adulthood, old age) each with associated roles. This usage differs from the more common usage in life course and youth studies in that it does not refer to people belonging to a shared period in history e.g., generation X'ers or baby boomers (Wyn and Woodman 2006). Rather, Priestley refers to generational categories and the relationships between them as mirroring the stratifications linked to social class or gender. Generational concepts such as childhood and adulthood are viewed as relational because they cannot exist except in relation to one another. Thus attention to these concepts helps in the analysis of how identities are (re)produced and intersect. We consider the intersection of generation in relation to masculinities and disability to raise critical questions regarding the meanings of these categories, including how individuals 'transition' between generations, when each begins and ends, and who is included or excluded. Similarly, masculinity is viewed as both a relational identity category and as a set of 'situated doings' that emerge in relation to time and place, and the interacting social positions of individuals (Connell 1995; West and Fenstermaker 1993).

\section{Study Participants}

The study was conducted in Toronto, Canada. Participants were recruited from a large regional children's rehabilitation centre that provides life-long services and supports for individuals with DMD from across the province of Ontario. Institutional ethics approval was obtained from the centre's Research Ethics Board. Eleven young men, ages 16 to 27 years old with Duchenne muscular dystrophy (DMD) participated in the study. All of the participants lived with parents/guardians and none were engaged in paid work. See Table 1 for further details.

\section{Data Generation}

The methods have been described in detail elsewhere (Gibson et al, in press). Briefly, we employed a multi-method qualitative design that included interviews, photo-elicitation and solicited narrative 
diaries. Photo-elicitation involved participants generating photographs that were used to enrich discussions in qualitative interviews. This method has been shown to ease rapport, provide a point of focus in interviews, and introduce relevant topics potentially unknown to the researcher (ClarkIbanez 2004; Croghan et al., 2008). Solicited narrative diaries were participant-generated audio recordings created for the study. The diaries were used to capture participants' priorities, subtleties of speech, and to provide them with control over what and when to record or erase (Milligan et al., 2005; Worth 2009). Like the interviews, the photos and diaries were viewed as reality constructing, meaning-making occasions that provided examples of 'doing identity work' where participants positioned themselves in a given way for a perceived audience (Jarvinen 2000). The data could thus be analyzed not only for participants' intentional choices but for the invisible structures that organize them (Bourdieu 1996).

Each participant was provided with an adapted digital recorder and digital camera and was asked to audio-record thoughts and take photos that reflected daily life, experiences of transitioning to adulthood, important relationships and activities, and representations of themselves as 'men'. For both activities they were encouraged to include anything they wished, but were also given a list of suggested topics, e.g., 'experiences or thoughts about your future and being or becoming an adult', and 'people, activities, places that are important to you'. Participants were asked over a two week period to take a photo and/or make a diary entry as many times as they liked but at least once a day. The photos and recordings were reviewed by the research team to identify potential lines of inquiry that could be explored in the final interview. Diaries entries and interviews were then transcribed.

The analysis procedures drew on techniques described by Miles and Huberman (1994) as follows. All data (interviews, diaries and photos) were analyzed to answer the research questions using a flexible coding and memoing approach derived from and consistent with the research objectives and the study's conceptual approach. Initial coding explored experiences, strategies, beliefs and representations of adulthood, disability, and masculinities. Inductive analyses were used to identify new themes and conceptual relationships. Multiple analytical cycles of further levels of abstraction facilitated the identification of patterns, recurring relationships, and conceptual congruence or incongruence. The multidisciplinary team held monthly meetings to discuss the main themes and impressions, develop explanations, and discuss alternate interpretations to guide further analysis. We also held two full day analysis meetings at the half way and completion stages of data collection. Two study participants acted as advisors and provided input on study procedures, interview questions, and emerging results.

In what follows, we describe the results of our analysis organized around a central theme we have labeled 'narratives of non-difference'. These were strategies used by participants to minimize their disabilities and claim putatively normal masculine and generational identities. We first provide an overarching description of the central theme, and then the details of its various forms and expressions. All names in the data are pseudonyms.

\section{Narratives of Non-difference}


In the participants' accounts, identities of disability, masculinity, and adulthood intersected in what we have labeled 'narratives of non-difference'. Within their photos, diaries and interviews, participants constructed self-narratives in which they presented themselves as both average and extraordinary. Average in that they were living ordinary lives with the same challenges, pursuits and interests as their non-disabled peers. Extraordinary in that they outlined how they had achieved these average lives in the face of the multiple challenges of living with DMD. Achieving a 'normal' life required substantial effort on the part of participants and their families in addressing challenges of fatigue, transportation, escalating care needs, loss of physical functions, and changing mobilities. In their accounts, the participants drew from their understandings of what it is to be a 'typical guy' amongst their peers to present themselves as 'normal' while recognizing their differences.

Three examples from the data are illustrative:

Jean Marc Diary: So today I'll talk a bit about myself. I'm a 17 year-old boy with Duchenne Muscular Dystrophy. I'd say, I try to live my life as a normal, as any other teen or pre-adult would. Umm, in school I really like science. So that's maybe one of my fields of study for university. Umm, also I like to play on the computer, watch TV, watch sports, play with my dog. So mostly things that everybody would do, as a normal teen or adult. But also there's other things [chuckles] that's a bit different: like, an (attendant) will help me out with stuff. So that's some of the things that are different from a normal teen and me. So there's a couple of differences. But I try to live my life as close to a teen, or the way I feel I want, basically.

$\sim$

Sameer Interview : There are people who I know who aren't disabled and are failing university, who aren't doing as well as me. And I think there's a difference there. So I like to think of it as, I have problems in one area, I have benefits in another area. You know? Everyone has their problems. It makes me feel normal.

$\sim$

Chris Diary: When having to engage with different females, it's hard for them to understand DMD, because they may find it kind of weird, like not normal. But we are normal.

In each of these examples, the participant works to establish himself as 'normal' in relation to peers, acknowledges differences and challenges secondary to his DMD, and reaffirms that these differences are not sufficient to negate membership in his (non-disabled) peer group. 'Normal' is referenced six times in these three short passages and was used commonly across the accounts. Participants' worked to establish that they were 'just like everyone else' took many forms, as discussed in more detail below, but they pervasively distanced themselves from other disabled youth and/or a disability self-identity. While the data provide insight into how participants performed their masculinities and generational identities (e.g., sports, school, dating) the distancing from disability identities was clearly foregrounded in the data and provided insight into how disability, masculinity and generation intersected for these young men.

Bourdieu suggested that marginalized groups have only two options to improve their social position: loyalty to the group through valorization of the properties stigmatized by the dominant social order - what might be termed in this context 'disability pride'; or assimilation to the dominant ideal and minimization of any apparent differences (Bourdieu 1984: 384). The data contained very little evidence of Bourdieu's first option but were replete with the second. In the 
dominant social order in which the participants were immersed, the stakes in successfully becoming an adult male were aligned with minimizing disability. The accounts reflect the many strategies employed by the participants that flowed from this understanding. Participants demonstrated how they had internalized the forms of capital that were valorized for young men, including successes in school and plans for work, independence, engagement with team sports as players or fans, and friendships. As we explore further below, participants reproduced and/or creatively reformulated some key forms of hegemonic masculinities, particularly related to sports, cars, action heroes, heterosexuality, expert knowledge (of DMD), interests in technology, computer science, and rationality/intelligence.

The dominant narratives of non-difference in the accounts do not suggest that participants were not fully aware of the multiple challenges of living with DMD. Rather the narratives can be viewed as a strategy, which may not be 'conscious' per se, but was employed to deal with an uncertain future and increasing loss of function. For the most part, participants did not challenge 'what counts' as normal or present counter-narratives that challenged dominant discourses of disability. They also had few recommendations to address barriers to participation in school, work and community. Rather, they functioned within the dominant social order and the 'rules of the game' vis-à-vis what it meant to be a "normal guy' across fields, and presented their lives and identities in relation to these uncontested parameters.

Below, we further delineate how narratives of non-difference were expressed in relation to other prominent themes in the data: dominant life trajectories, maintaining a 'positive attitude', and independent living. We then discuss how participants further constructed and negotiated their identities (disability, adulthood, masculinity) through claims of non-difference.

\section{Dominant Life Trajectories $=$ School $->$ College $->$ Work}

Across the accounts, a dominant trajectory of transition and development was consistently reproduced. This trajectory was focused on scholastic achievement and can be represented as school-> college-> work = successful transition to adulthood. Again a story of non-difference emerged. Participants stressed the desire to do well in school and often spoke about, and took pictures of, their academic awards. Post-secondary school was a taken for granted life-stage and discussed at length in the interviews. Plans were discussed, action taken, hard work was needed, and successes were celebrated. Four of the six participants who were in high school were focused on post secondary education - what college or university to choose and what they would study. All expressed interest in computer related fields. Four other participants had completed college/university and were engaged in some form of work (Michael -unpaid writer, Shyam - co-op placement, Chris - volunteer) or were looking for work (Peter) and all were seeking steady paid employment. All, except one participant (Jeff), spoke in some way about future work or career choices. They cited several reasons why finding work was challenging: uncertainty regarding how to go about the process; disability was seen as a barrier by employers; difficulties with transportation; and fatigue limiting their abilities to work full time.

Participants faced considerable challenges with traditional employment. They could not drive and accessible public transit was limited, they would need attendant care support at work, they were 
largely limited to computer-based tasks, their morning routines took considerable time and assistance, and they were vulnerable to fatigue. The progressive nature of DMD also meant that each of them would be requiring ventilator assistance within the next few years, which would create increased need for assistance. Thus while it was possible to work and to do so successfully, the combination of impairment effects, accessibility barriers, and possible discrimination, made working very difficult. Despite these challenges none of the participants questioned the assumptions that paid work was the next step in their lives or discussed possible alternatives. Work was viewed as both an end in itself that signaled social membership and inclusion, and as a means towards staying occupied.

Chris Diary: Being stuck at home, it's so hard, because you always feel tired. And you know, with someone like me, who has DMD, it's so hard to get out of the house. And I just want to get out of the house, you know, to be like everyone else, go to work, come home, you know.

Participants did not directly acknowledge their reduced life expectancy, but the stories presented were those of truncated trajectories that did not often extend beyond taking up first paid work. Peter, for example, discussed how his life had been focused on finishing school and college and now he was rather suddenly faced with 'figuring things out'. There was a suggestion in Peter's account that his uncertain prognosis at least partially accounted for a lack of planning beyond graduation. Sameer who was attending university made this link somewhat more directly:

I: Okay. Now imagine yourself in five years. Tell me about what you see.

Sameer: Someone who finished school, uh, working [Laughs]. Honestly I haven't really looked that far ahead. But [sigh] I can tell you what I would hope to see.

I: What do you hope to see?

Sameer: You know being in the shape that I'm in ...you know, physically. Um, also I hope to be, um, um, working and, um. I mean [sigh] [pause] it's really tough to say.

Work was nevertheless seen as an important life pursuit and a 'next stage' after school was completed for the majority of participants. Chris noted that paid employment was important both for practical reasons but also as a marker of adult success in his family and their Chinese culture.

Chris interview: If someone asks, 'Hey, where are you working?' I can say, 'Oh, at that place'. I don't know how much they will pay, but I'll just tell someone I get paid. In Chinese culture it's important you have a job. Someone will look up to you if you have a job. Like, if you're like 20 something and you don't have a job - they find that kind of weird, my relatives.

School and work were thus linked with development towards adult status which is consistent with other research with disabled people demonstrating that work is a powerful marker of adulthood, particularly for men (Brown et al., 2009; Willis al., 2001). These compelling incentives to work extend beyond financial gains, conferring social status and inclusion and helping to establish positive social and self- identities. Within this context, participants saw their escalating impairments as personal challenges that made pursuit of these goals more difficult, but they did not question that work was worthwhile pursuing. There were no counter-narratives in the data, and little questioning or resisting this path - other than to delay the pursuit of work. 


\section{Maintaining a Positive Attitude}

The notion of 'keeping positive' recurred across the accounts and was aligned with narratives of non-difference. Keeping positive meant not engaging with thoughts about decline, impairments, and death. Sameer was particularly reflective regarding the development of his positive attitude and its function. He recalled an incident as a boy when he met an 'older guy' with DMD (likely in his 20s) who had much more severe impairments and who said, 'you will be like me someday'. Sameer viewed this as a 'negative' attitude and was motivated to work hard to maintain his abilities and 'stay healthy'. For him, negativity was linked with discussing decline and death, while positivity meant focusing on his abilities rather than disabilities. Linked to his positive attitude was the idea that he must 'keep on going' which he repeated many times:

I: What's important to you in your life right now?

Sameer: Uh, just to keep on going. [Laughs] Just to keep on continuing, never giving up on things, that's something I really do strive for. Determination is a big thing in my life. You know there are challenges, times when things are a little harder, you just want to not deal with them, um, especially with, like, a disability. [pause] But yeah, if I wasn't determined, I don't know what kind of person I would be. Especially having DMD you can't be the kind of person who gives up easily.

Two other examples are illustrative:

I: Why is that an important thing, to have a positive attitude?

Peter: [pause] Like so you won't become depressed and stuff. And negativity would have that type of effect.

$\sim$

I: So who would you say might be a role model?

Mark: Terry Fox.

I: Oh, okay. Tell me about that.

Mark: Well, he had a positive attitude. Like, he was (pause) disabled too. Um, he fought through his cancer battle. And I know that I can fight through this too, muscular dystrophy.

Maintaining a positive attitude was thus presented as an active, deliberate strategy for addressing uncertainty and decline. By not engaging with these issues in their daily lives, participants felt able to ward off depression and stay engaged with daily life. Positivity, however, also closed off opportunities to share and address negative emotions or moments of ontological insecurity, provided less opportunity to seek comfort and support, or rally social and political forces to effect improvements in accessibility. These risks relate to what has been labeled the 'tyranny of cheerfulness' in the cancer literature (King 2006:103). Hints of so-called negative emotions were in the accounts. Mark for example frequently referred to feeling 'stressed', Jeff expressed undirected anger, and Shyam grieved the loss of his physical abilities. These kinds of expressions were nevertheless largely minimized, avoided, or deliberately suppressed.

\section{Independent Living}

A tension between maintaining narratives of non-difference and the realities imposed by a progressive disabling condition was apparent in participants' discussions regarding moving out of their family homes. There was a full range of plans discussed across the accounts, from participants 
who had no intention to ever leave the family home, to those who were actively preparing for it. These differences were partly related to life stage, family ethno-cultural norms, and/or how participants viewed it as typical or not:

Sameer Interview: A lot of older friends of mine who've finished university years ago... they're like in their mid-20's, still living at home. And a lot of others lived at home until they got married. That's kind of the norm in my friend and family circle.

There was often a sense that moving out was something participants would do 'someday' but not now, either because they felt they were too young, would need more financial resources (Michael), were not prepared (Peter), or would wait until they had a partner (Chris). Attendant care, the skills to direct care, and the loss of the good care provided by family were among the challenges that made moving out somewhat daunting.

Peter Diary: Okay, my thoughts on becoming an adult are about living independently on my own. And also getting a job. At the present time, I'm still thinking about independent living. At this moment I'm not ready but I am interested in living on my own one day.

Peter later elaborated that he could only focus on one at a time - finding work or moving out - and was currently focused on looking for work because living on his own would be a 'full time job'.

As with school and work, moving out was consistently discussed as an achievable but challenging milestone that marked entry into adulthood and minimized differences associated with disability:

I: So what do you think would be the difference between being a teenager and being an adult? Joey: Not living with your parents.

$\sim$

Chris: I would want to live with somebody (if I moved out).

I: Why is that?

Chris: I don't know, I would feel like a grown up man. Like, and also maybe relatives would look up to me as, like, 'oh Chris his disability, it's not ruining his lifestyle.' I don't know, I don't wanna feel left out.

Participants also struggled with their desire for independence and abandoning the expert care provided by their families. In the following, Jean Marc reproduces normative discourses of independence while discussing the difficulties of losing his family as primary caregivers.

Jean Marc Diary: But the big challenge is accepting the idea that somebody else other than your mom or dad or family will help you out with daily living things. And also, it's a bit of a learning curve, because you have to learn how to direct your care. But it's a good experience cuz it lets you become a bit more independent, and not always dependent on your family.

\section{Doing Identities: Disability}

In presenting their stories, participants constructed DMD largely as an individual problem that they addressed in a number of ways. Prominent amongst these were the attitudinal strategies of 'keeping positive'. In doing so they resisted narratives of pity and 'poor quality of life' that permeate healthcare, education and the broader community. They emphasized their 
achievements, particularly scholastic, and credited their personal attitudes and the support of their families in helping them achieve success. The accounts contain very few comments regarding the disabling environment i.e., modifiable structural, material or attitudinal barriers that contributed to their disablement, suggesting that the participant had not been exposed to disability rights or other political disability discourses.

Participants varied on identifying themselves as 'disabled' or not. Some participants labeled themselves this way, others did not, and still others were strongly opposed to it. Nevertheless all, to a greater or lesser degree, worked within their accounts to minimize or distance themselves from a disability identity. Shyam for example, made a distinction between a 'disability' and a 'condition', whereby disability was described as caused by something a person does, and a condition was described as something that is 'not your fault':

Shyam Diary: I don't really like it when people use the word 'disability'. Disability sounds as if a person is broken. But people with DMD are not broken. They have a medical condition which causes their muscles to deteriorate over time. For example, when someone has cancer, and their health deteriorates, people do not say they have a disability.

Similarly, Chris, Michael and Sameer each made comments to distance themselves from others with disabilities. Chris said his non-disabled friends were 'more normal' than his disabled friends. Michael, Shyam, and Sameer each discussed a perception that other disabled people had negative attitudes, were not working as hard as they could, and had 'given up'. They worked within the interviews to present themselves as different from this group and instead claimed membership with their non-disabled peers.

Michael: I find that other people my age with this disability, they kind of give up on life.

I: Oh. Can you speculate why?

Michael: Cause they pity themselves, I don't know.

I: So what makes you different?

Michael: I have big goals and I want to change things. And I'm smarter than the average person.

Michael's comment regarding his intelligence was reiterated by Mark who stated that youth with DMD are, 'very intelligent'. These comments can be viewed as strategic identity claims. By signaling that they possessed a particular form of valorized, masculine capital, participants claimed an identity of non-difference where they not only establish membership with their non-disabled peers, but suggest that they can successfully compete within scholastic fields.

\section{Doing Identities: Adulthood and Masculinities}

Participants spoke specifically about ways in which they felt like, or were treated as, adults. Some participants explicitly identified as adults, but younger participants often referred to themselves as teenagers or even kids. For example:

Joey Diary: I'm not turning into an adult yet. I'm still a teenager, and I think after high school, I'll be more there. 
Joey added that living apart from his parents and advocating for himself would also contribute to establishing his adulthood. Jean Marc said he felt like an adult "when people I see make me involved in decisions that influence me or affect me." In both cases, adulthood was linked with independent decision making. This idea was repeated across the accounts.

Perhaps not surprisingly, participants struggled with discussing the notion of being a man or 'guy', likely a difficult topic for most youth. Although participants photographed and discussed stereotypical masculine interests, such as sports, fast cars and violent video games, they did not necessarily explicitly connect these with their masculine identities. Joey, for example, struggled when asked to imagine a picture that represented him as 'a guy':

Joey: A violent video game.

I: Why would you say that?

Joey: Actually no, that's a little sexist because girls play video games too. So I guess something a girl would find nasty. Because girls are always saying, 'Guys are pigs!' [said in a feminized voice]. Yeah, okay, we're pigs, fine then. So, I don't know, a picture of a pig.

Different forms of masculine capital were revealed that varied with the participants' temporal field positions. Working or planning to do so, as discussed above, held currency in imagined adult worlds and positioned participants as moving towards membership in these fields. Other expressions of masculinity such as Joey's reference to violent video games served to position participants' masculinities in relation to their contemporary peer groups (although they may also hold currency in some adult fields).

While the younger participants more often related 'being a guy' to their interests (video games, sports, and technology). Older participants directly related manhood to sexuality and experience. For Michael, 'being a guy' was linked with heterosexuality:

I: So which picture do you think represents who you are as a man?

Michael: Maybe that the girl at the mall. Because she's pretty. If that's not too shallow!

I: No, that's okay. [Michael laughs] Is there anything else?

Michael: Well it proves I'm not gay.

Few participants spoke about intimate relationships and most seemed uncomfortable when the topic was raised. Only one participant, Chris, spoke directly about the importance of sexual experience:

Chris Interview: I think it just shows, after they lose it (virginity), they become a man.

Other aspects of masculinity that were prominent in the accounts and reflected in the quotes above included intelligence, scholastic achievement and diligence/hard work. Identities and traits that run counter to hegemonic masculinities included an emphasis on positivity, kindness, and caring: 
I: If someone were to walk into your room and hadn't met you before, what do you think they would say about you?

Mark: "You're a cool guy." [both laugh]

I: Because of all the sports things?

Mark: The sports stuff, yeah.

I: Anything else?

Mark: "You're a joyful, nice, person" I guess, yeah.

\section{Discussion: Reconsidering Transitions}

We have discussed the many ways narratives of non-difference were reproduced across the accounts in relation to school, work, family, and relationships. Non-difference constituted a point of intersection of masculinities, disability and generational identities. Our analysis focused on participants' strategic expressions of the habitus and how they established membership and success within different 'identity fields' (Coles, 2009). Narrative habitus, as described by Frank (2010) provided a conceptual tool to interrogate the relationship between structure and agency in the construction and constant re/negotiation of identities in everyday practices. Narratives both create and sustain an individual's habitus and are continually revised in light of exposure to new stories, new experiences, and new realities. Children with DMD are born into a particular sociocultural context with dominant trajectories of work and social life. These are not predetermined, but are however delimited in the sense that there are dominant social stories for which exceptions prove the rule. The study illuminated how the forms of capital across social fields were internalized by participants and expressed as 'normal' whereby normative bodies, lives, relationships and trajectories were pursued and rewarded. Pursuit of normality was conscious and effortful, but the reasons why it was valorized were less likely to be questioned. Rather as part of the habitus it was known, deeply ingrained as 'who I am' or 'not for the likes of me'. The narrative habitus is the expression of these deeply ingrained dispositions whereby stories serve to strategically construct, maintain, and reproduce identities.

Narratives of non-difference reproduced by the participants served to distance them from the atypical aspects of daily life, and diminish inconsistencies with the identity of 'a normal guy'. Scholarly excellence and the pursuit of work and independence were available forms of capital within expected trajectories to adulthood. Within these limited fields, participants related stories of typical and successful trajectories. Decline, death, uncertainty, chronic fatigue, anger, fears for the future, or increasing care burdens for family were not prominent stories in their accounts. This is likely because these stories would not function to maintain identities that are consistent with their habitus. The accounts make it clear that the participants had limited, if any, alternative narratives/resources to draw from in constructing their narratives. In other words, there was no other narrative map of DMD to draw from in which they may recognize themselves in positive ways. They thus drew from what was available to them, the transition trajectory that is typical for their non-disabled peers, but they did so in an open and emergent way - as if to say ' $I$ 'll figure the rest out later if I get there'. Limited fields (school, work, family) were accessed and other fields or activities within these fields, with a few exceptions, were largely absent (e.g., dating/marriage, travel, recreation/sport). 
Because DMD is a condition that almost exclusively affects males, it is difficult to draw conclusions regarding the relationship between narratives of non-difference and masculinities. Indeed our project from the outset has been cautious of the possibility of extricating different identities into neat silos because they are intimately interdigitated within the habitus and its expressions. Nevertheless, it is instructive to compare our results to the gendered practices identified by Willis et al (2001) in their interviews with young women and men with cystic fibrosis (another congenital progressive condition with an uncertain lifespan). Their research demonstrated that the young men had markedly higher career aspirations than the young women, and men were highly involved in planning for future careers, financial independence, and 'proving their intellectual ability'. Moreover young women were more likely to openly discuss concerns about declining health, fear and depression and their uncertain futures. The male participants, on the other hand, conveyed a 'sense of denial' about the progressive effects of the condition. They variously stated that they 'choose not to think about', 'put it aside', and 'keep goin" in much the same way that the participants in our study also focused on 'keeping going' and 'staying positive'. In another convergence, the young men in Willis et al's study also were less likely to associate with other young people with cystic fibrosis. These overlaps with our results, and the differences with young women, suggest that narratives of non-difference may be particularly aligned with disabled masculinities. Further research is needed.

Research with other groups of young people with disabilities and chronic illness (Williams et al., 2009; Robinson 1993; Atkin and Ahmad 2001; Angst 2001) has illuminated how families construct and maintain 'life as normal' by focusing on the typical aspects of family life. Williams et al (2009) in their UK study of youth with cystic fibrosis found that maintaining normality within the family resulted in continual 'biographical revision' in anticipation of the declining illness trajectory. Borrowing from Pound et al(1998), they describe this process as 'biographical anticipation', meaning that young people and their families were constantly shifting and reappraising their understandings of 'normal' while striving for continuity of experience. Narratives of non-difference powerfully reproduced families' understandings of disability as something to be overcome by normalizing family life, albeit through extraordinary efforts.

Individuals with DMD and their families are not oblivious to the disconnects between their lives and those of non-disabled peers and address these differences in a number of creative ways. These include all their efforts to overcome obstacles that would relegate them to the margins of community life. In the course of the study, participants shared pictures of how homes has been adapted to ensure accessibility and comfort; they spoke proudly about excelling at school, their friends, and about personal traits of positivity and perseverance. They also drew on other illness narratives to acknowledge they are 'fighting the good fight' against DMD. This was exemplified in Mark's comment about fighting DMD like Terry Fox 'fought through his cancer battle'. This was not a story of beating DMD, but about thriving despite the challenges and uncertainties of progressive illness. Participants' accounts reflected an understanding of adult behavior norms such as moving out, but their creative strategies for adopting these norms allowed them to stay at home until the right conditions were in place. 
Little is known about how gender and/or impairment type influences the transitions needs and experiences of youth with various impairments. As this study and others have demonstrated, transitioning to adulthood for individuals with shortened and uncertain life spans raises a number of questions that have not been given due consideration to date. These include: Should (all) children be encouraged to take up the norms and practices of adulthood? What criteria should be used to assess what constitutes a successful transition? How does gender intersect differently with various impairments? Should young people be encouraged or dissuaded from moving away from parents? According to what criteria?

Questions such as these suggest larger questions about how a right and proper adulthood is understood in society, and whether conformity to these expectations is always best for disabled youth. In health care and education what constitutes 'good' transition outcomes is largely taken for granted. These ideas are consistent with notions common in western societies that the entrance to adulthood is marked by achievement of residential and financial independence, as well as the attainment of emotional self-reliance, cognitive self-sufficiency and behavioral self-control, perhaps especially, but not exclusively, for boys. Children internalize these roles and what it means to successfully achieve adulthood which can have profound effects on youth whose lives do not conform to typical social or physical developmental trajectories. These effects can be both positive and negative and related to myriad details of supports, opportunities, resources etc. Anxiety, depression, feelings of worthlessness, or 'nothing to offer' may be offset by learning to live well in the present, improved health behaviours, a deeper appreciation of important relationships and improved 'self-management' (Gibson et al., 2009, Willis et al. 2001; Lindsay et al.,2011)

We are by no means suggesting that transition programs are universally harmful or should be abandoned. What we are advancing, however, is that an unreflective pursuit of normal can paradoxically increase inclusion while amplify marginalization. Pursuing particular activities allows young men with considerable impairments entry into particular fields, but for the most part they remain marginalized in these fields. In earlier research (Gibson et al., 2007), we found that men with DMD (ages 26 to 35 years) living on their own had developed alternate strategies for dealing with this marginalization, including rejecting school and work and focusing instead on sustaining relationships with friends and families and 'enjoying the little bit of time I have left'. These life choices of 'living well in the present' (Davies, 1997) do not figure in the current transitions rhetoric and we suspect many professionals working in transitions programs might struggle with supporting them. Nevertheless we suggest that only focusing on approximating normative life trajectories closes off other possibilities that may in some cases better suit young people's needs and abilities. For example, so-called leisure activities may take on a greater significance, as may hobbies, caring for others, sustaining relationships, or managing one's own care needs. These activities, because they are oriented to the present and not future development, may judged as futile, trivial or wasteful and are less likely to be supported or funded (Gibson et al., 2009, Aitchison, 2003). Priestley (2003: 132-142) has similarly critiqued the centrality of work, productivity and independence as central markers of transitions and adult social status. Moving away from thinking of transition to adulthood as a delimited linear pathway opens up multiple other pathways that could also be explored with young people and their families. These kinds of explorations help to create spaces for different ways of living that contribute to the acceptance of differences. Practice 
and research thus might address alternatives for thinking about a good transition, a good adulthood, or a good childhood (or problematizes these categories, see Priestley 2003) that does not reference the trajectories of nondisabled peers.

With regards to the study methods, the combination of photographs, diaries and interviews was helpful in providing rich and varied contexts for participants to perform their identities. No one method was more successful than others in capturing identity practices, and the affinity for one method over another varied across the participants. Diary and photo methods provided an entry into capturing practices and perspectives that might be challenging to articulate, or intimidating to discuss in a face-to-face context. The photo and diary activities also provided participants with time, space and impetus to reflect on, and later share, their experiences. Elsewhere we discuss in more detail the different kinds of data produced by each method and how, as well as the value/drawbacks of the combined approach (Gibson et al, In press).

\section{Conclusion}

This research investigated the transitions experiences of young men with DMD and suggested that masculinities, disabilities and generational identity strategies intersected through narratives of non-difference. Through these narrative strategies, participants constructed, maintained and reproduced gendered identities of normality. The study contributes to emerging scholarship that critically examines the intersectionality of disability and gender for young people with life long impairments. Shuttleworth et al. (2012) have recently called for more nuanced research into disabled masculinities that explores how masculinities intersect differently with different impairments and how 'context and life phase contribute to this dynamism'. To that end we hope that our focus on progressive congenital conditions, and specifically DMD, contributes to emerging scholarship in the field. Moreover we would suggest that 'doing generation' is as much a part of ongoing identity negotiations as is doing gender (West and Fenstermaker, 1993) or doing disability (Brown et al., 2009). Where gender, disability, and generation intersect will vary across individual and social contexts. Scholarship that closely considers the intricacies of these relationships is better equipped to capture unique identity strategies of those with, for example, acquired versus early onset impairments. Further research is needed to advance this promising area of inquiry.

\section{Acknowledgements:}

We would like to thank the study participants and the following individuals for their assistance with the study: Doug Biggar, Vivien Harris, Nadia Serrao, and Kathleen McLeod.

\section{Funding:}

This work was supported by the Canadian Institutes of Health Research (grant number 103245). 


\section{References}

Abbott D (2012) Other Voices, Other Rooms: Reflections on talking to young men with Duchenne muscular dystrophy (DMD) and their families about transition to adulthood. Children \& Society 26 (3): 241-250.

Aitchison C (2003) From leisure and disability to disability leisure: developing data, definitions and discourses. Disability and Society 18(7): 955-969.

Angst D (2001) School-age children. In: M Bluebond-Langner, B Lask and D Angst, eds, Psychosocial aspects of cystic fibrosis. London: Arnold: 125-138.

Atkin K and Ahmad WIU (2001). Living a 'normal' life: young people coping with thalassaemia major or sickle cell disorder. Social Science and Medicine 53(5): 615-626.

Beresford B (2004) On the Road to Nowhere? Young Disabled People and Transition. Child: Care, Health and Development 30(6): 581-587.

Berge JM, Patterson JM, Goetz D and Milla C (2007) Gender differences in young adults' perceptions of living with cystic fibrosis during the transition to adulthood: A qualitative investigation. Families, Systems, \& Health 25(2): 190-203.

Binks JA, Barden WS, Burke, TA and Young, NL (2007). What do we really know about the transition to adult-centered health care? A focus on cerebral palsy and spina bifida. Archives of Physical Medicine and Rehabilitation 88(8):1064-1073.

Bjarnason DS (2002) New voices in Iceland. Parents and adult children: juggling supports and choices in time and space. Disability and Society 17(3): 307-326.

Bourdieu P (1997) Pascalian Meditations. Stanford: Stanford University Press.

Bourdieu P (1996) Understanding. Theory, Culture and Society 13(2): 17-37.

Bourdieu P (1990) In Other Words. Essays Towards a Reflexive Sociology. Stanford, California: Stanford University Press.

Bourdieu P (1984) Distinction, A Social Critique of the Judgement of Taste. Cambridge: Harvard University Press.

Bourdieu P and Wacquant LD (1992) An Invitation to Reflexive Sociology. London: University of Chicago Press.

Brown K, Hamner D, Foley S and Woodring J (2009) Doing disability: Disability formations in the search for work. Sociological Inquiry 79(1): 3-24. 
Clark-Ibanez M (2004) Framing the social world with photo-elicitation interviews. American Behavioral Scientist 47(2): 1507-1527.

Coles, T. (2009). Negotiating the Field of Masculinity: The Production and Reproduction of Multiple Dominant Masculinities. Men and Masculinities, 12(1): 30-44.

Connell RW (1995) Masculinities. Berkeley: University of California Press.

Croghan R, Griffin C, Hunter J and Phoenix A (2008) Young People's Constructions of Self: Notes on the Use and Analysis of the Photo-Elicitation Methods. International Journal of Social Research Methodology 11(4): 345.

Davies ML (1997) Shattered assumptions: time and the experience of long term HIV positivity. Social Science and Medicine 44(5): 561-571.

Frank AW (2010) Letting Stories Breathe: A Socio-Narratology. Chicago: University of Chicago Press.

Gibson BE, Mistry B, Smith B, et al. (in press) Integration of Audio Diaries, Photography and Interviews in Research with Disabled Young Men. International Journal of Qualitative Methods.

Gibson BE, Young NL, Upshur REG and McKeever P (2007) Men on the margin: A Bourdieusian examination of living into adulthood with muscular dystrophy. Social Science and Medicine 65(3): 505-517.

Gibson BE, Zitzelsberger H and McKeever P (2009) 'Futureless persons': Shifting life expectancies and the vicissitudes of progressive illness. Sociology of Health \& IIIness 31(4): 554-568.

Jarvinen M (2000) The Biographical Illusion: Constructing Meaning in Qualitative Interviews. Qualitative Inquiry 6(3):370-391.

King S (2006) Pink Ribbons, Inc: Breast Cancer and the Politics of Philanthropy. Minneapolis, MN: University of Minnesota Press.

Lindsay S, Kingsnorth S and Hamdani Y (2011). Barriers and facilitators of chronic illness self-management among adolescents: a review and future directions. Journal of Nursing and Healthcare of Chronic Illness 3(3): 186-208.

Miles MB and Huberman AB (1994) Qualitative Data Analysis: An Expanded Sourcebook. Thousand Oaks: Sage Publications.

Milligan C, Bingley A and Gatrell A (2005) Digging deep: Using diary techniques to explore the place of health and well-being amongst older people. Social Science \& Medicine 61(9): 1882-1892. 
Morris J (2002) Moving into Adulthood. Report, York: Joseph Rowntree Foundation.

Pound P, Gompertz P and Ebrahim S (1998) Illness in the Context of Older Age: The Case of Stroke. Sociology of Health and IIIness 20(4): 489-506.

Powers K, Hogansen J, Geenen S, Powers LE and Gil-Kashwabara E (2008) Gender matters in transition to adulthood: A survey study of adolescents with disabilities and their families. Psychology in the Schools 45(4): 349-364.

Priestley M (2003) Disability: A Life Course Approach. Malden, MA: Polity Press.

Priestley M, Rabiee P and Harris J (2003) Young disabled people and the 'new arrangements' for leaving care in England and Wales. Children and Youth Services Review 25(11): 863-890.

Robinson CA (1993). Managing Life with a Chronic Condition: The Story of Normalization. Qualitative Health Research 3(1): 6-28.

Shakespeare T (1999) The sexual politics of disabled masculinity. Sexuality and Disability 17(1): 5364.

Shuttleworth RP (2000) The search for sexual intimacy for men with cerebral palsy. Sexuality and Disability 18(4): 263-282.

Shuttleworth R, Wedgwood N and Wilson NJ (2012) The Dilemma of Disabled Masculinity. Men and Masculinities 15(2): 174-194.

Sparkes A and Smith B (2002) Sport, spinal cord injury, embodied masculinities, and the dilemmas of narrative identity. Men and Masculinities 4(3): 258-285.

Sparkes Ac, Pérez-Samaniego V and Smith B (2012) Social comparison processes, narrative mapping and their shaping of the cancer experience: A case study of an elite athlete. Health: 16(5): 467-488.

Stewart DA, Law MC, Rosenbaum P and Willms DG (2001) A qualitative study of the transition to adulthood for youth with physical disabilities. Physical and Occupational Therapy in Pediatrics 21(4): 3-21.

Walkerdine V (1993) Beyond developmentalism. Theory \& Psychology 3(4): 451-469.

West C and Fenstermaker S (1993) Power, Inequality, and the Accomplishment of Gender: An Ethnomethodological View. In: England P (ed) Theory on Gender, Feminism on Theory. New York: Aldine Transaction, pp. 151-174. 
Williams B, Corlett J, Dowell JS, Coyle J and Mukhopadhyay S (2009) "I've Never Not Had it So I Don't Really Know What it's Like Not to": Nondifference and Biographical Disruption Among Children and Young People With Cystic Fibrosis. Qualitative Health Research, 19(10): 1443-1455.

Willis E, Miller R and Wyn J (2001) Gendered embodiment and survival for young people with cystic fibrosis. Social Science and Medicine 53: 1163-1174.

Worth N (2009) Making Use of Audio Diaries in Research with Young People: Examining Narrative, Participation and Audience. Sociological Research Online 14(4):

<http://www.socresonline.org.uk/14/4/9.html>.

Wyn J and Woodman D (2006) Generation, Youth and Social Change in Australia. Journal of Youth Studies. 9(5):495-514. 
Table 1: Participant Characteristics

\begin{tabular}{|l|c|c|c|}
\hline Name & Age & Education & Parents' region of birth \\
\hline Emilio & 16 & In highschool & Latin America \\
\hline Joey & 16 & In highschool & Canada \\
\hline Mark & 16 & In highschool & (Indo) South America \\
\hline Albert & 17 & In highschool & Southeast Asia \\
\hline Jean Marc & 17 & In highschool & Canada \\
\hline Jeff & 19 & In highschool & North Africa \\
\hline Sameer & 21 & In university & China \\
\hline Peter & 23 & Completed college/university & China \\
\hline Chris & 24 & Completed college/university & South Asia \\
\hline Shyam & 24 & Completed college/university & Canada \\
\hline Michael & 27 & Completed college/university & \\
\hline
\end{tabular}

